\title{
Predictors of endoscopic colorectal cancer screening over time in 11 states
}

\author{
Lee Mobley $\cdot$ Tzy-Mey Kuo $\cdot$ Matthew Urato $\cdot$ \\ John Boos $•$ Nancy Lozano-Gracia $\cdot$ Luc Anselin
}

Received: 19 February 2009/Accepted: 10 November 2009/Published online: 28 November 2009

(c) The Author(s) 2009. This article is published with open access at Springerlink.com

\begin{abstract}
Objectives We study a cohort of Medicare-insured men and women aged 65+ in the year 2000, who lived in 11 states covered by Surveillance, Epidemiology, and End Results (SEER) cancer registries, to better understand various predictors of endoscopic colorectal cancer (CRC) screening.

Methods We use multilevel probit regression on two cross-sectional periods (2000-2002, 2003-2005) and include people diagnosed with breast cancer, CRC, or inflammatory bowel disease (IBD) and a reference sample without cancer.

Results Men are not universally more likely to be screened than women, and African Americans, Native Americans, and Hispanics are not universally less likely to be screened than whites. Disparities decrease over time, suggesting that whites were first to take advantage of an
\end{abstract}

L. Mobley $(\bowtie) \cdot$ T.-M. Kuo · M. Urato · J. Boos

RTI International, 3040 Cornwallis Road, Research Triangle

Park, Durham, NC 27709-2194, USA

e-mail: 1mobley@rti.org

T.-M. Kuo

e-mail: mkuo@rti.org

M. Urato

e-mail: muratot@rti.org

J. Boos

e-mail: jboos@rti.org

N. Lozano-Gracia

World Bank, Washington, DC, USA

e-mail: nlozano@worldbank.org

L. Anselin

Arizona State University, Tempe, AZ, USA

e-mail: luc.anselin@asu.edu expansion in Medicare benefits to cover endoscopic screening for CRC. Higher-risk persons had much higher utilization, while older persons and beneficiaries receiving financial assistance for Part B coverage had lower utilization and the gap widened over time.

Conclusions Screening for CRC in our Medicare-insured sample was less than optimal, and reasons varied considerably across states. Negative managed care spillovers were observed, demonstrating that policy interventions to improve screening rates should reflect local market conditions as well as population diversity.

Keywords Colorectal cancer screening - Spatial heterogeneity - Utilization disparities - Socio-ecological model $\cdot$ Spatial interaction $\cdot$ Managed care spillover

\section{Introduction}

Although colorectal cancer (CRC) is one of the few neoplastic diseases that can be prevented through screening, and survival rates are $90 \%$ if diagnosed early, only $39 \%$ of CRC cases are diagnosed at an early stage. Age-specific incidence and mortality rates show that most cases are diagnosed after age 50 , so screening recommendations target people aged 50 or older [1-3]. In 2004, only $45.1 \%$ of the over-50 population had received endoscopic CRC screening within the 5-year interval 2000-2004 [4]. This increased to $55.7 \%$ within the 10-year interval 1997-2006 [5]. These national statistics suggest that CRC screening rates are increasing slowly over time for both men and women but remain suboptimal and are higher for men than for women [5-9]. CRC remains the second leading cause of cancer deaths in the United States [10, 11], so meeting screening guidelines is important. 
There are several known risk factors for CRC, but highrisk groups account for only about a one quarter of the CRC incidence. Thus, regular population screening is important because any policy limiting screening to highrisk groups would miss the majority of CRC cases [3]. However, it is especially important for high-risk groups to be screened regularly, which may include people with previous breast cancer or CRC and inflammatory bowel disease (IBD).

The literature offers conflicting evidence regarding whether breast cancer survivors have greater risk for CRC [12-16], but the National Cancer Institute includes a personal history of breast cancer as a CRC risk factor [17]. IBD is associated with increased risk of CRC [18], and continuous endoscopic surveillance is recommended for persons with IBD [19]. Continuous endoscopic surveillance is also recommended for CRC patients and survivors [20]. The recommended short 1-year interval for surveillance colonoscopy following CRC resection has been shown to be a clinically efficient and cost-effective strategy for improving detection and reducing mortality [21].

The main objective of this paper is to study a large elderly population that is well insured by fee-for-service (FFS) Medicare, including persons with known risk factors for CRC, to determine the personal and environmental factors that are important predictors of CRC screening utilization and to examine trends in utilization over time. Since 1998, Medicare has covered sigmoidoscopy every 4 years for all persons over age 50 and colonoscopy every 2 years for persons at high risk for CRC. With benefits expansion in 2001, Medicare now covers colonoscopy every 10 years for persons of average risk [22, 23].

During our study period, a controversy arose in the medical literature regarding appropriate endoscopy use for CRC screening in elders, considering their increased risk of adverse outcomes from endoscopic tests [24-26]. In 2008, the U.S. Preventive Services Task Force (USPSTF) recommended that CRC screening should decline with age and recommended against endoscopic screening for persons aged $85+[25]$.

Along with personal factors, such as age, we examine environmental factors reflecting service supply and the spatial interaction of people and their environments along the pathways to endoscopic CRC screening. We study two time periods (2000-2002 and 2003-2005) to assess changes in relationships over time. We use multilevel probit regression of the binary outcome "whether screening was utilized," examining people in 11 states in separate regressions. Recent descriptive work has demonstrated considerable geographic variation in endoscopic CRC test use across states [22], which we explore fully in statespecific regressions. We advance the literature by examining multiple, multilevel factors associated with the varied geospatial outcomes. We focus on the following research questions and examine differences across the states and over time:

1. After adjusting for other factors, are there disparities in endoscopy use by sex, race, or ethnicity?

2. After adjusting for other factors, is there lower endoscopy use by needy elderly who receive assistance for paying Part B premiums (covering endoscopy services)?

3. After adjusting for other factors, how pronounced is the decline in use with age?

4. After adjusting for other factors, is endoscopy utilization higher among high-risk populations?

5. Are there significant Medicare managed care market penetration spillover effects on the propensity to utilize endoscopic CRC screening by the FFS Medicare population?

We perform parallel empirical analyses in an early (2000-2002) and later (2003-2005) time period using a cohort of people present in both periods to assess disparities over time in response to the Medicare benefit expansion that began in the early period and the emerging guidelines, which recommend decreased endoscopic screening with advancing age.

\section{Methods}

\section{Study population}

Our study population is a cohort of 272,077 men and women in 11 states aged 65 or older in the year 2000, enrolled in FFS Medicare (both Part A and Part B) in 2000, and remaining alive over the period 2000-2005. Beneficiaries who subsequently lost or dropped Medicare Part B (elective coverage that can be purchased to cover outpatient services, such as endoscopy) or who had Medicare managed care coverage during the period would have incomplete claims histories for endoscopic procedures. Less than $1.5 \%$ of the study population was without complete FFS coverage for the entire period, and we kept them in the sample and controlled statistically for their "variable insurance" coverage over the period (variables: months without Part B, months with Medicare managed care coverage). Thus, our cohort represents the typical insurance experience of Medicare beneficiaries who were encouraged to try Medicare managed care organizations during this period. Beneficiaries could voluntarily enroll and disenroll from Medicare managed care organizations on a monthly basis, and plan switching and returning to FFS Medicare was common as Medicare beneficiaries shopped around for the best value [27, 28]. Thus, even 
though our sample members were primarily in FFS Medicare, they had neighbors with Medicare managed care coverage, and some tried it themselves. Because the SEERMedicare database has higher representation in markets where Medicare managed care is well established, we use this situation to examine the results for indication of Medicare managed care spillover effects onto our Medicare FFS population.

\section{Conceptual model and sample statistics}

Our conceptual model (Fig. 1) is a hybrid of several models from the behavioral health, socio-ecological, and health geography fields [29-31]. This conceptual model situates the individual decision maker-characterized by enabling, predisposing, and need constructs from the classic Aday model [32] —into an ecological context that has different zones of influence defined as Fundamental/ Macro, Intermediate/Community, Interpersonal/Proximate, and Individual/Population. Many factors at the different levels of hierarchy are included in the conceptual model diagram. We are not able to include variables reflecting all of these constructs in our empirical work, because data are not available. However, in future research, inclusion of these omitted variables may provide new insights. Constructs represented by variables included in our model are highlighted in bold text in Fig. 1.

All variables used in the regression modeling and their sources are described in Appendix Table 3, which is divided into three sections corresponding to the conceptual model. Person-level sample statistics are presented in Appendix Table 4. Intermediate, community-level factors are defined at the county level, reflecting the political units defined to manage the public finances associated with community services. The Interpersonal, neighborhoodlevel factors are defined at a smaller geographic resolution than the community factors, the primary care service area (PCSA). PCSAs are natural primary care physician markets derived by Dartmouth researchers using Medicare patient flows to primary care physicians, which have been validated in previous work [29, 30, 33, 34]. PCSA and countylevel variable sample statistics are presented in Appendix Tables 5 and 6 .

We include a new measure of Medicare managed care penetration at the PCSA level in the regression equation, which we derived from $100 \%$ Medicare denominator files. In previous studies, Medicare managed care penetration has always been measured at the county level, because county-level data are publicly available. PCSAs are arguably more appropriate as market areas for managed care than counties, because they reflect primary care markets. As shown by comparing Appendix Tables 5 and 6, PCSAs are much more numerous and smaller than counties; the state of Connecticut, for example, has eight counties covered by 71 PCSAs.

\section{Statistical analysis}

Our outcome of interest is endoscopic procedure utilization, defined as any type or amount of endoscopic

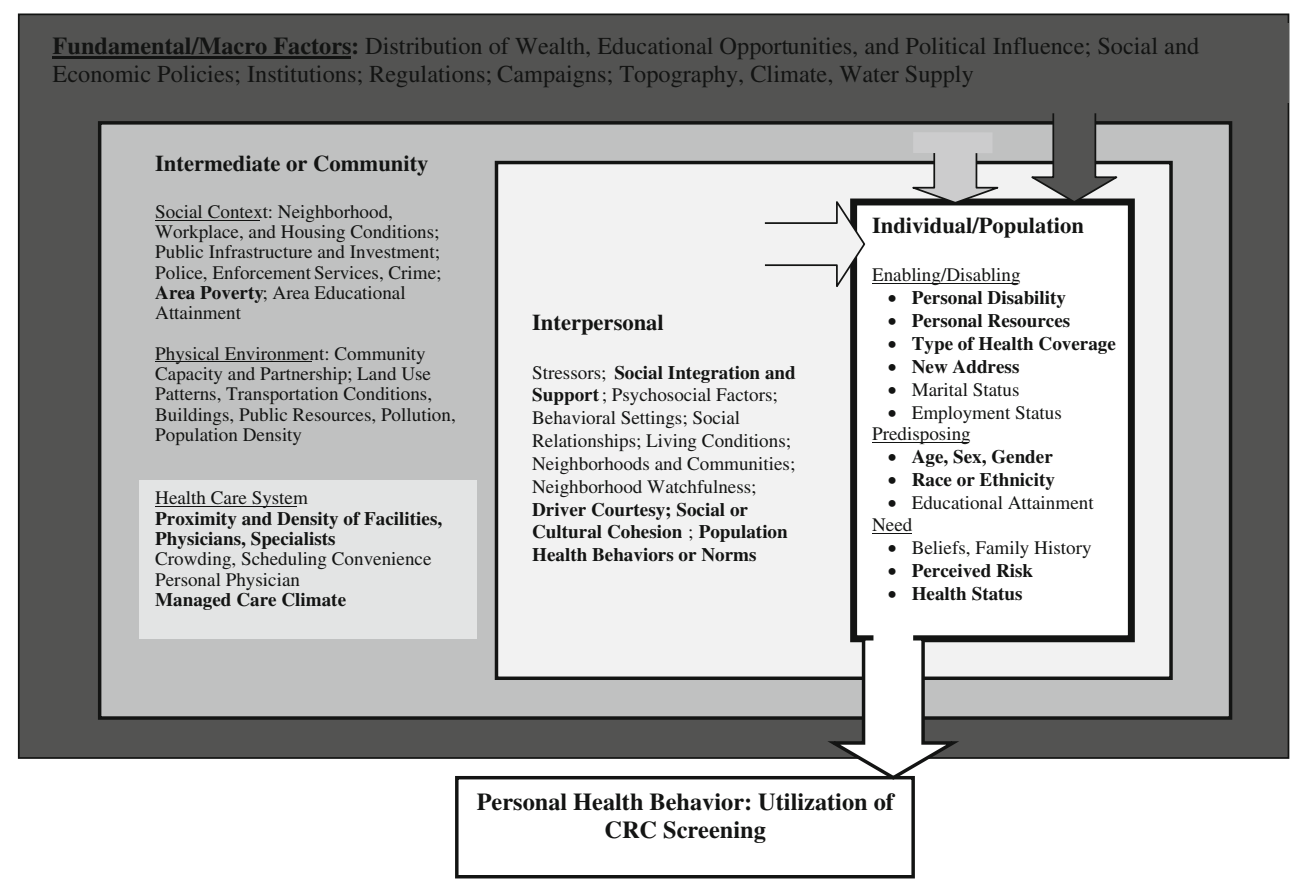

Fig. 1 Socio-ecological multilevel model of colorectal cancer screening behavior 
procedure use over each 3-year period. We estimate multilevel probit models of the probability of using endoscopic procedures and include person-level, PCSA, and countylevel covariates, following our conceptual model (see Fig. 1). We use generalized estimating equations (GEE) to adjust the standard errors of area-level variables to reduce the efficiency bias caused by redundancy (repeated measures over all people in the area) [35-37].

Pooling states together in a single empirical model with fixed effects to produce some "national" results may not make statistical sense when there is interest in the considerable heterogeneity that exists across the states [31]. We estimate each state model as a separate regression, with two time periods: early (2000-2002) and late (2003-2005).

\section{Results}

As presented in Table 1, across the 11 states we study, between 45 and $53 \%$ of the study cohort used endoscopy services at least once over the 6-year period 2000-2005, which is far from optimal. This population is well insured by Medicare, which expanded benefits to cover this service for people of average risk in 2001, so the low use rates are a concern. Table 1 presents that the proportion of people who used endoscopy at least twice over 2000-2005 ranges from 14 to $19 \%$ across the 11 states. These repeat users are probably persons at higher risk for CRC than the average person in the cohort (those with breast cancer or CRC diagnosis or IBD).

To save space and sharpen the focus, we do not discuss all of the empirical results from our estimation, although these are provided for interested readers in Table 2. Table 2 presents state-specific results with early and late time periods in adjacent columns for each state. Only the coefficient estimates that were statistically significant at the $5 \%$ level or better are included in the table with the exception of the last variable, where $p$ values (in parenthesis) follow the estimates (managed care spillover effects). We include weaker results, significant at the $10 \%$ level or better, for the managed care spillover effects variable because of the policy importance of this effect, which reflects the degree of Medicare managed care spillover effects on FFS Medicare beneficiaries. The last row of the table is the model prediction success rate, which is good, ranging from 71 to $80 \%$ across the states and time.

In Figs. 2, 3, 4, 5, and 6, we present the results that can help answer the five main study questions. The results portrayed are effect estimates from the binary probit model, interpreted as marginal probability effects that arise from the fully specified/fully adjusted empirical model (see Table 2).

Disparities by gender, race, or ethnicity

Women appear less likely to use endoscopy than men in all but four states: Georgia, New Mexico, Kentucky, and Louisiana. In Georgia and New Mexico, there is no difference; in Kentucky and Louisiana, women are more likely to use these services than men. Figure 2 illustrates the relative difference in the propensity for women versus men to use endoscopic screening for CRC over time, as the cohorts age. A negative 0.03 is interpreted as "females are

Table 1 Use of endoscopy in 2000-2005 by sample cohort of well-insured persons (cohort aged 65+ in the year 2000, followed through 2005)

\begin{tabular}{|c|c|c|c|c|c|}
\hline State & $\begin{array}{l}\text { Sample size } \\
\text { in state }\end{array}$ & $\begin{array}{l}\text { Proportion with any } \\
\text { use in } 2000-2002\end{array}$ & $\begin{array}{l}\text { Proportion with any use in } \\
2003-2005 \text { but not } 2000-2002\end{array}$ & $\begin{array}{l}\text { Proportion with any } \\
\text { use in both periods }\end{array}$ & $\begin{array}{l}\text { Proportion with any } \\
\text { use in } 2000-2005\end{array}$ \\
\hline $\mathrm{CA}$ & 86,843 & 0.31 & 0.23 & 0.14 & 0.47 \\
\hline $\mathrm{CT}$ & 23,402 & 0.36 & 0.27 & 0.17 & 0.53 \\
\hline GA & 10,316 & 0.37 & 0.26 & 0.17 & 0.53 \\
\hline IA & 22,799 & 0.38 & 0.24 & 0.19 & 0.53 \\
\hline KY & 18,203 & 0.32 & 0.23 & 0.15 & 0.47 \\
\hline LA & 15,717 & 0.29 & 0.23 & 0.14 & 0.46 \\
\hline MI & 25,692 & 0.37 & 0.25 & 0.19 & 0.53 \\
\hline NJ & 35,378 & 0.33 & 0.23 & 0.17 & 0.48 \\
\hline NM & 7,439 & 0.30 & 0.21 & 0.14 & 0.45 \\
\hline UT & 8,777 & 0.34 & 0.26 & 0.15 & 0.51 \\
\hline WA & 17,511 & 0.34 & 0.26 & 0.15 & 0.51 \\
\hline
\end{tabular}

We used the following codes on Medicare claims to identify endoscopy use:

CPT codes: 44388-44397, 45300-45392; HCPCS codes: G0104, G0105, G0121; and ICD-9-CM codes: 45.22-45.25, 45.41-45.43, 48.22-48.24, 48.36

We used ICD-9-CM codes 555.x and 556.x listed on the Medicare claims to identify persons with IBD 


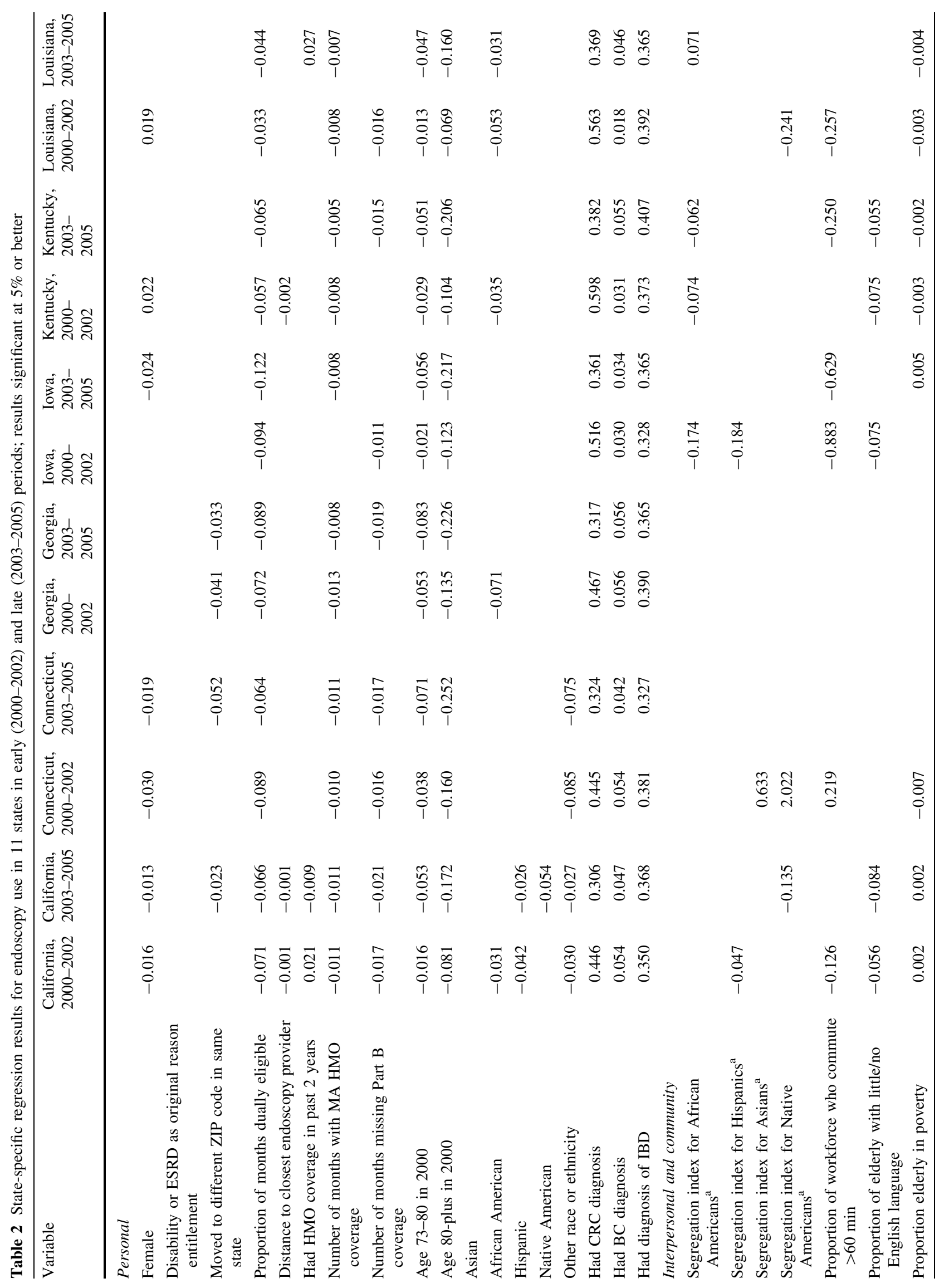




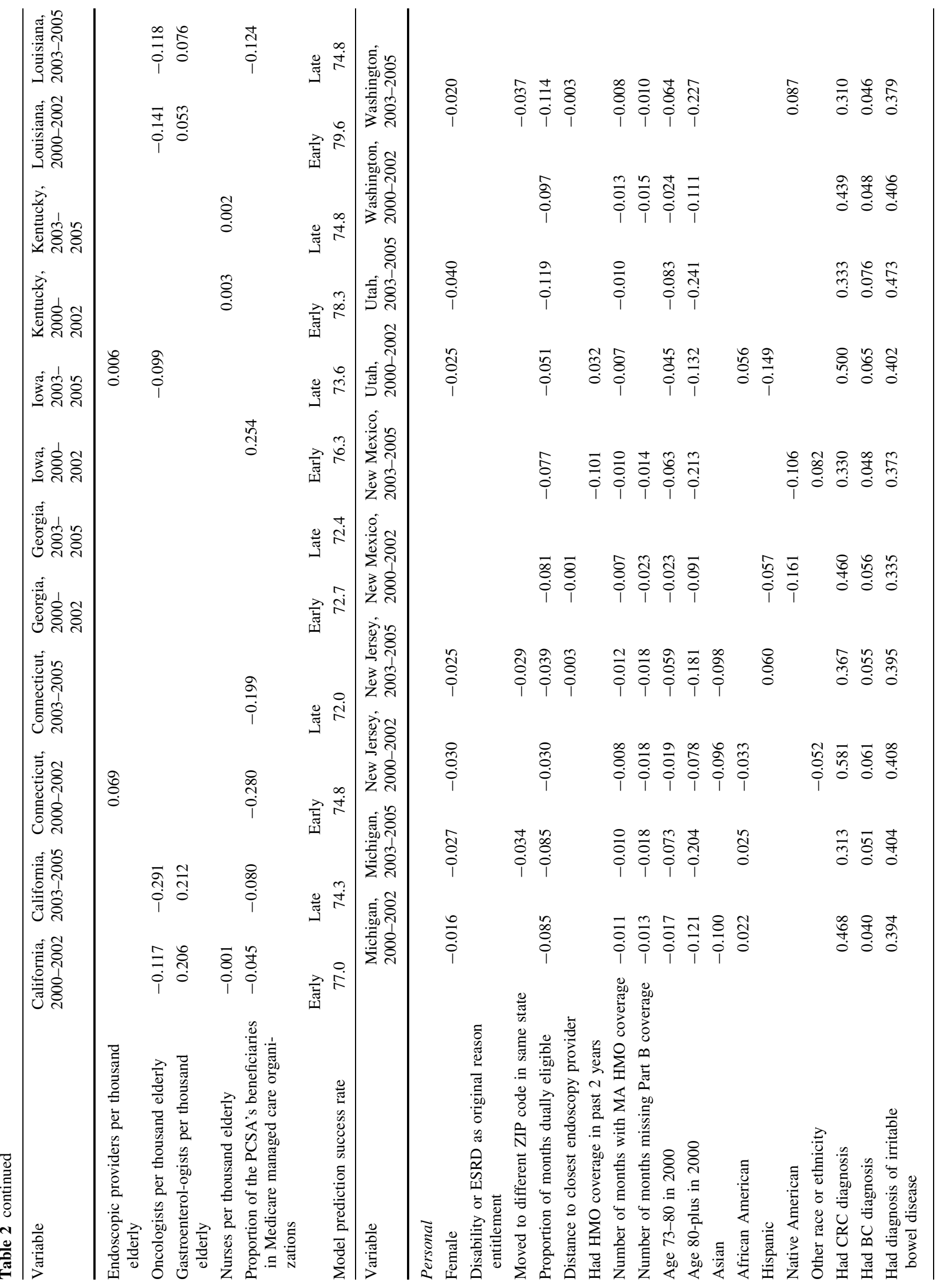




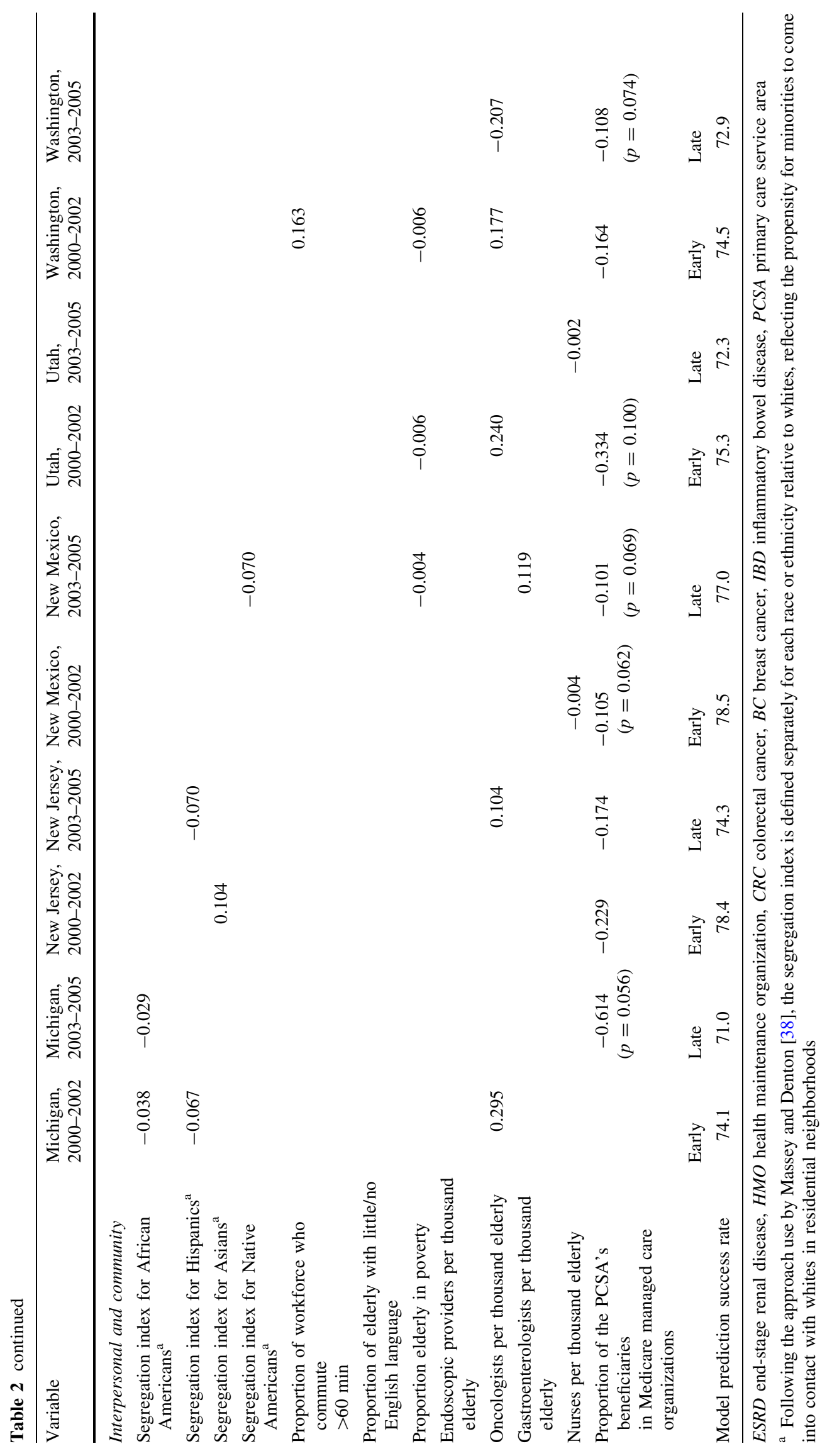


Fig. 2 Relative propensity to use endoscopic services among a female cohort when compared with a male cohort by state and time, in early (2000-2002) and late (2003-2005) periods

Fig. 3 Relative propensity to use endoscopic services among minority groups relative to whites by state and time, in early (2000-2002) and late (2003-2005) periods
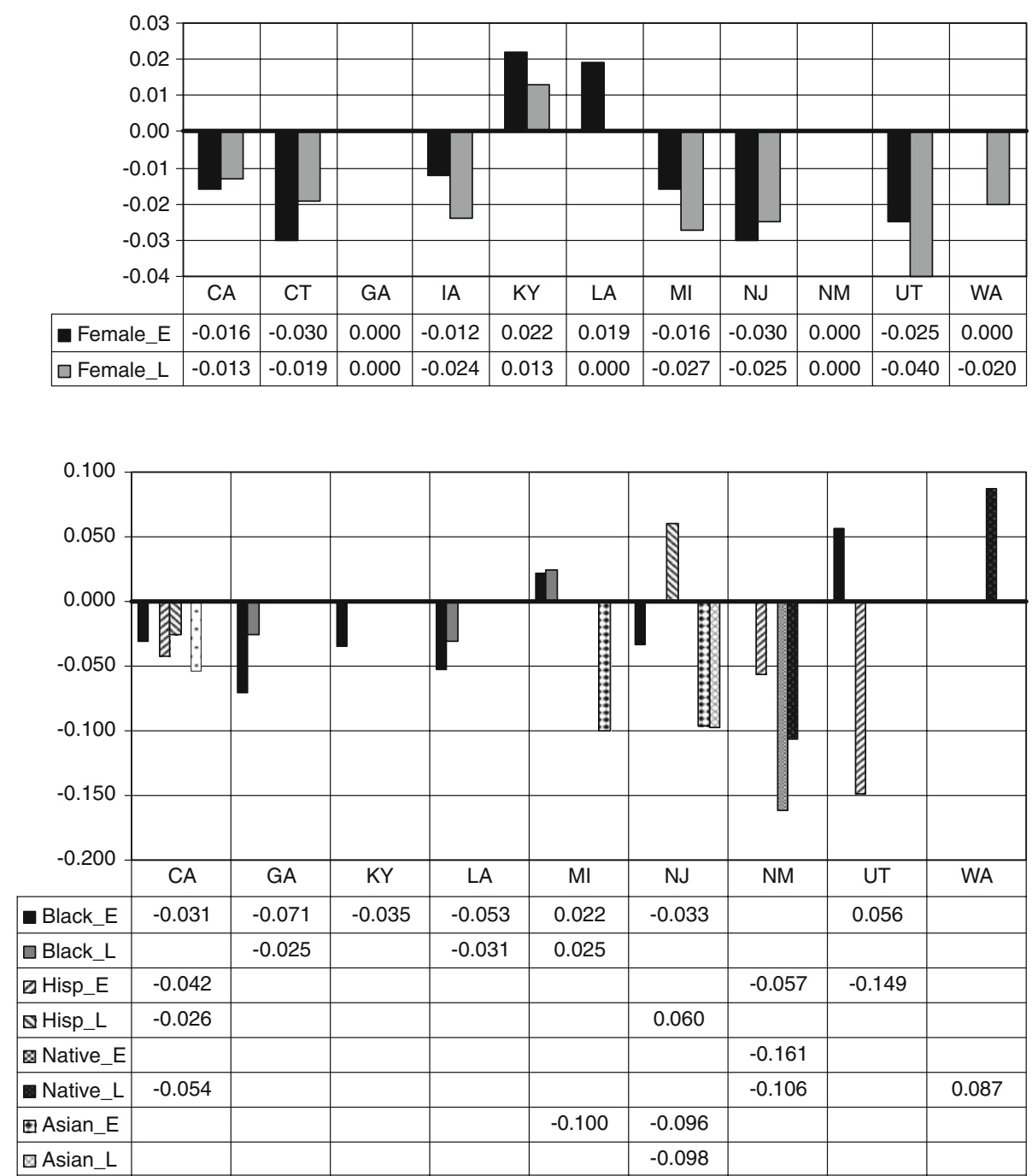

Fig. 4 Proportion of aged beneficiaries in the states who are dually eligible, and the estimated effect of dual eligibility on use, in early (2000-2002) and late (20032005) periods

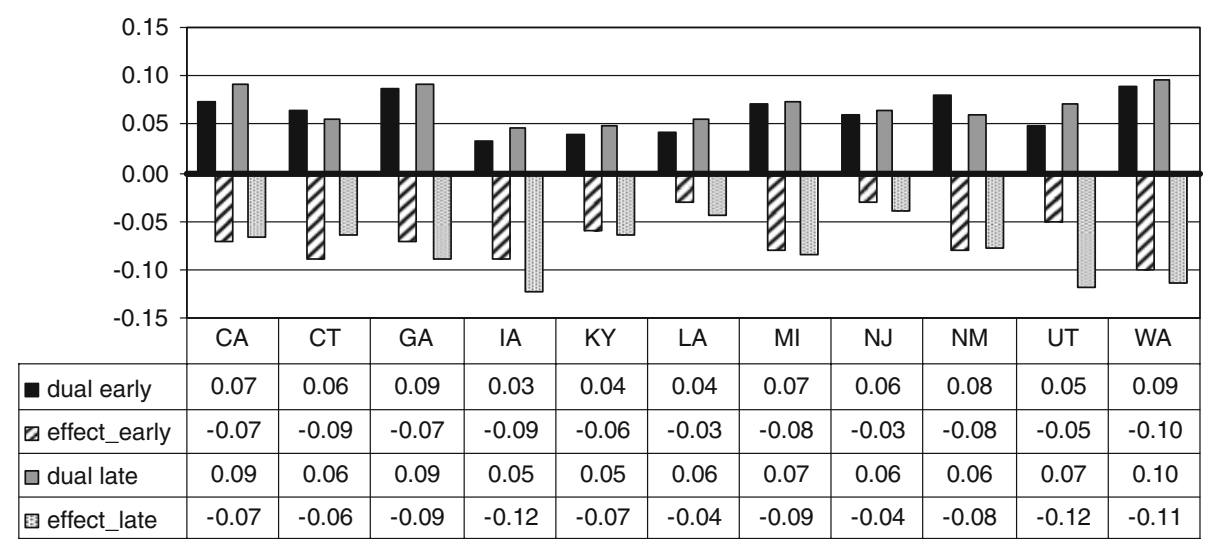

$3 \%$ less likely, on average, than males to use endoscopy in this state and time period."

Race and ethnicity effects vary across the states. Blacks are significantly less likely to use endoscopy than whites in several states: California, Georgia, Kentucky, Louisiana, and New Jersey (see Fig. 3). However, disparities appear to have narrowed over time. By the later period, black-white disparities existed for only two states-Georgia and Louisiana-and they were smaller than in the previous period. In two states (Michigan and Utah), disparities were in the opposite direction: blacks were significantly more likely than whites to use endoscopy. In California and New 
Fig. 5 Decline in probability of endoscopy utilization with age, relative to the youngest age group (aged 65-72), in early (2000-2002) and late (20032005) periods

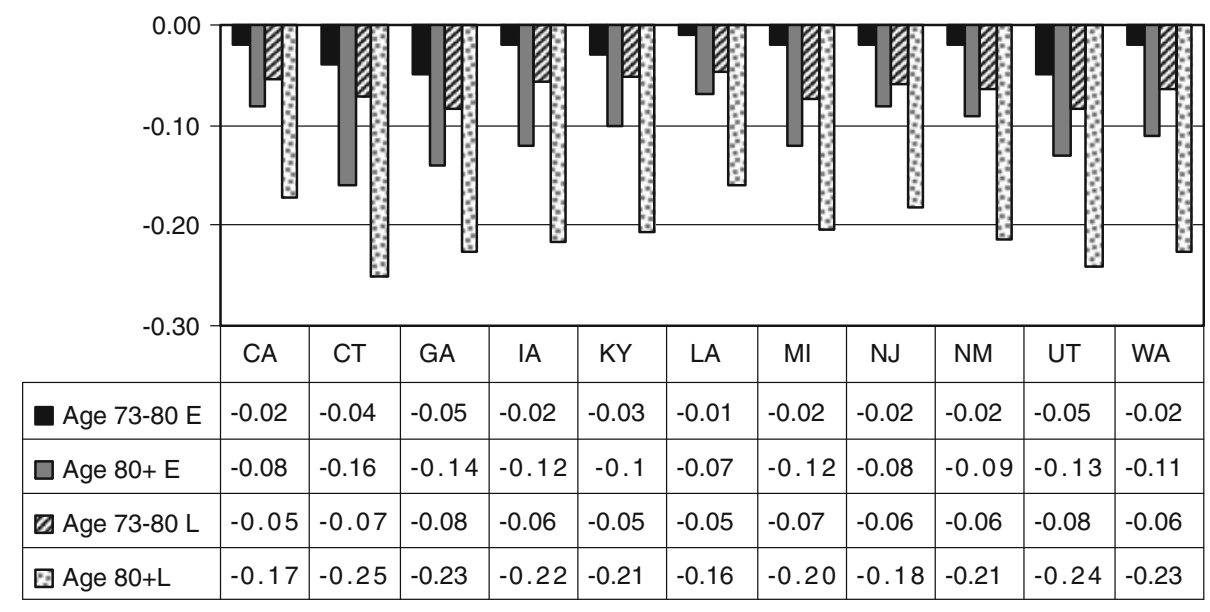

Fig. 6 Endoscopy use by breast cancer and colorectal cancer survivors and those with inflammatory bowel disease, in early (2000-2002) and late (2003-2005) periods

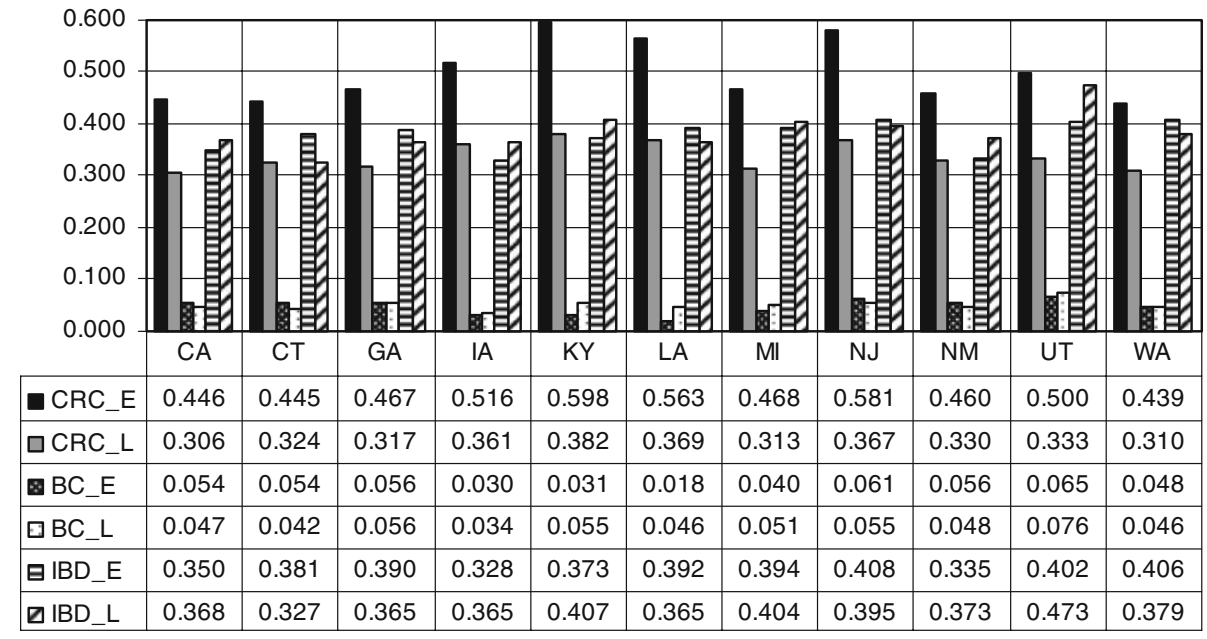

Mexico, Hispanics and Native Americans had lower probability of use (4-6\%) than whites. Hispanics had much lower probability of use than whites in Utah (about 15\% lower) but higher probability of use than whites in New Jersey (about 6\% higher). Asians had lower probability of use than whites in Michigan and New Jersey (about 10\% lower). Native Americans had higher probability of use than whites in Washington (about 9\% higher). In two states (Connecticut and Iowa), there were no observed statistically significant racial or ethnic disparities in the predicted probability of endoscopy use.

Financial need

Having dual eligibility for Medicare and Medicaid, with extra resources to purchase Part B coverage, is associated with lower probability of use in every state and in both time periods. This variable is indicative of lower financial means, and findings demonstrate that the poorer elderly are less inclined to use these services, even when covered by Part B insurance. Figure 4 shows a state-level variable, the proportion of aged beneficiaries in the states who are dually eligible (black, gray), as background to help interpret the estimated effect of dual eligibility on use (striped, spotted), for the early (2000-2002) and late (2003-2005) time periods. In Utah, Iowa, and Washington, these estimated effects are large, suggesting at least $10 \%$ lower probability of use for dually eligible seniors. California is the only state with an increasing proportion of dually eligible seniors statewide coupled with a decline in the estimated reduction in propensity to use endoscopy over time, suggesting increased social support for this subgroup. More research may be needed regarding other factors that discourage utilization by low-income seniors, such as social support or cultural factors that may discourage use.

\section{Effects of aging}

National CRC incidence rates from the period 1998-2002 by age from the National Cancer Institute [1] show that people aged 65-74 accounted for $26 \%$ of incidence, whereas those aged 75-84 accounted for $29.2 \%$ of 
incidence and those aged $85+$ accounted for $12.6 \%$ of incidence. Thus, in our cohort of people aged $65+$ in the year 2000, the national incidence rates cited above suggest that screening of older beneficiaries was quite important.

Our data span the time when Medicare coverage was expanded to include screening for persons of average risk. In the early period (2000-2002), we would expect to see higher use by older persons (aged 73+) than younger persons (aged 65-72) if utilization was based solely on risk. Instead, our data show that the estimated probability of utilization declined with advancing age group. Relative to the youngest group (aged 65-72), use was lower in the middle group (aged 73-80) and even lower in the oldest group (aged $80+$ ). These age disparities are shown by state in Fig. 5. Connecticut shows the greatest disparity in use with age, and 7 of 11 states show at least $10 \%$ lower use among the oldest group relative to the youngest group.

\section{Utilization by high-risk populations}

Persons with IBD and breast cancer survivors may be at higher risk for developing CRC, and continuous endoscopic surveillance is recommended for CRC patients and survivors. Thus, we would expect to see higher utilization rates for these groups if greater risk translates into greater utilization of screening. Figure 6 shows the estimated impacts of these three factors relative to persons without these factors, in the early and late periods. Among the states, Utah exhibits the highest endoscopy use by breast cancer survivors and those with IBD, relative to others in the population without these conditions. In every state, utilization by CRC patients and survivors and persons with IBD is much greater than for persons without these conditions. It is interesting that for CRC patients and survivors, use drops over time as the cohort ages. This is not universally true for persons with IBD, where in six states use increases as the cohort ages.

\section{Managed care spillover effects}

Greater penetration by managed care can change the way medicine is practiced in an area, with spillover effects on FFS Medicare costs and outcomes [39]. However, the evidence of managed care's impacts on the use of preventive services is not consistent. Breast cancer screening rates may be higher in regions with higher HMO penetration in Medicare and the private sector [40-42]. Increased cancer screening of various types has been associated with HMO enrollment [43]. Although use of endoscopic procedures for CRC screening was not examined, HMOs promoted the use of fecal occult blood testing (FOBT) for
CRC [43]. Few studies have examined the impact of managed care on endoscopic CRC screening. However, a recent study using the Medicare Current Beneficiary Survey found that Medicare managed care plans seemed to favor FOBT over endoscopic procedures, when compared to FFS Medicare [44]. FOBT can detect cancer, but endoscopic procedures, which cost more, can actually prevent cancer by removal of precancerous lesions. One study by Ponce et al. [45] found that the type of managed care market structure may affect endoscopy use rates, with associated disparities in use for minorities versus whites. Thus, whether or not HMO presence in the market spills over positively (or negatively) to increase (or decrease) utilization of endoscopy by older persons with FFS Medicare is an empirical question.

The last variable in Table 2 is the Medicare penetration of local PCSA markets. When the estimated effect of this variable is positive (Iowa), the spillover effect from Medicare HMOs in the market is positive. When it is negative, the spillover effect is negative. In our data, only Iowa exhibits positive Medicare managed care spillover effects; other states show negative spillover effects (California, Connecticut, Louisiana, Michigan, New Jersey, New Mexico, Utah, and Washington). Only Georgia and Kentucky show no HMO spillover effects. These findings warrant further study, which is policy relevant but beyond the scope of this paper.

\section{Discussion}

Strengths and limitations

The Surveillance, Epidemiology, and End Result (SEER)Medicare database chosen for the study population in this paper is ideal for several reasons. The database combines men and women with a previous breast cancer or CRC diagnosis from the cancer registry populations in 11 states, combined with a randomly selected reference sample of people without a previous cancer diagnosis from the Medicare 5\% enrollment files. All Medicare claims submitted by physicians or outpatient facilities are available for both populations, which allow us to identify those with IBD. The SEER-Medicare database provides a large, only somewhat representative sample of the Medicare population; thus, it cannot be used to generalize to national-level statistics. However, it provides a sample that is useful for examining utilization behavior in different states, which are well represented.

The complete 5\% Medicare sample is randomly drawn and thus expected to be nationally representative, but the 11-state portion of it (covered by the 11 SEER cancer registries) may not be nationally representative. Similarly, 
the SEER registry population may not be nationally representative of all persons with cancer. However, the people aged 65 and older residing in the SEER registry states are known to be comparable to those in the non-SEER states based on age and sex distributions [46]. The SEER registry states have slightly more affluent, more urban populations and a higher proportion of non-white individuals than the non-SEER states, and the SEER cancer registry population has lower mortality than cancer populations in non-SEER states [46]. Thus, our study sample is slightly more urban, wealthier, more ethnic, and less likely to die from cancer than populations in the states we do not study. The main advantage of using these SEER-Medicare data for the analysis is that breast cancer and CRC survivors and persons with IBD can be identified and included in the study. Continued screening is especially important for these groups, as noted earlier. Another advantage is that the SEER areas have much higher penetration by Medicare HMOs than nonSEER areas [46], making them more useful for assessing whether there are significant managed care practice spillover effects, one of our main study questions.

\section{Discussion of findings}

Other variables in Table 2 thought to impede utilization of endoscopy for CRC screening are related to transportation and travel: distance to closest endoscopy provider, commuter intensity, or having recently moved to a new residential ZIP code. Distance to closest provider is significant in only four states (California, Kentucky, New Jersey, and Washington), and effects are very small (1-3\% decrease in probability of use for a 10 mile farther facility). This effect is small because 10 miles is a large change relative to the norms of travel indicated by sample statistics (mean distance is between 1 and 5 miles among the states, with 10 miles representing about 2 standard deviations from the mean). Commuter intensity has a negative effect in California, Iowa, and Kentucky, as expected if greater commuter intensity makes driving more unpleasant for the elderly. However, this is not the case in two states where the estimated effect of commuter intensity is positive (Connecticut and Washington). Having moved to a different ZIP code has a negative effect on probability of endoscopy use in six states (California, Connecticut, Georgia, Michigan, New Jersey, and Washington) and ranges from $-2 \%$ in California to $-5 \%$ in Connecticut. This effect is much larger than the effect of increasing distance to closest provider by 10 miles. Taken together, these findings suggest that for elective services, such as endoscopy, distance to closest provider is less important than local driving conditions or being disrupted by moving or unfamiliar with the best routes to or from one's neighborhood, a byproduct of moving to a new residence.
Higher residential racial or ethnic segregation at the local neighborhood level may either improve or impede social integration and support [30, 31, 47-50]. Findings demonstrate that residential segregation affects endoscopy use differently across the states and over time, with sometimes positive and sometimes negative effects. Thus, we cannot conclude that living in residentially segregated neighborhoods is necessarily detrimental to preventive health behaviors. Other factors thought to be associated with use are acculturation, area poverty, and supply of providers. Acculturation factors, which reflect differences in the ability to speak English by recent versus historical immigrants from other countries, have been found to be important for Latinos [51]. We find that living in communities where a greater proportion of the elderly have poor English language ability is associated with lower endoscopy use in California, Iowa, and Kentucky. Living in communities with a greater proportion of elderly in poverty has a negative effect in Connecticut, Kentucky, Louisiana, New Mexico, Utah, and Washington, and a positive effect in California and Iowa. The positive effect in California is consistent with the growing dually eligible population there and observed improvements in their utilization of endoscopy over time, noted earlier.

Several recent studies have highlighted the need to assess the capacity available to perform endoscopy to detect CRC [52-57]. In 2002, 14.2 million colonoscopies were performed; this number was anticipated to increase because of the increased use of colonoscopies for screening and the general aging of the population. Because capacity varies across the country, geographic differences in availability are likely to persist, if not increase. However, we find that the density of endoscopy providers has a positive effect in only two of the 11 study states: Connecticut and Iowa. We also examine density of medical specialists associated with endoscopy supply, such as gastroenterologists and oncologists. We find that the density of oncologists per thousand elderly is associated with lower endoscopy use in California, Iowa, and Louisiana but higher use in Michigan, New Jersey, and Utah, with mixed findings for Washington. The density of gastroenterologists greatly increases use in California (20\% higher probability per additional gastroenterologist per thousand elderly) with more modest positive effects in New Mexico $(+12 \%)$ and Louisiana $(+5-8 \%)$.

Answers to main research questions

National statistics suggest that women and minorities are less likely to use endoscopy than men or whites. We find that national statistics conceal local variation that goes against the norm, based on the 11 states we study. For 
example, we find that women in Kentucky and Louisiana had slightly $(1-2 \%)$ higher probability to use endoscopy services than men in their states. Also, African Americans in Michigan and Utah had higher probability to use endoscopy than whites in those states (2.5 and 5.6\%, respectively), Hispanics had higher probability to use services than whites in New Jersey (6\%), and Native Americans had higher probability to use services than whites in Washington (8.7\%). More generally, we find that disparities in utilization among whites, African Americans, and Hispanics narrowed over time. These findings suggest that whites were first to take advantage of the expansion in Medicare coverage in most states. Perhaps, state comprehensive cancer control efforts help tip the balance in favor of minorities in some states.

Results demonstrate that breast cancer survivors are more likely to use endoscopy, as are CRC patients and survivors and persons with IBD. These are higher-risk groups, so higher probability of use among them is optimal and suggests that translational medicine is being practiced. However, observed trends in endoscopy use with age (another risk factor) are cause for concern. Although older people (aged 75 or older) are more likely to be diagnosed with CRC than younger elderly (aged 65-74) [1], our data demonstrate that the probability of endoscopy use is much lower for older than for younger seniors. Another cause for concern is the lower use of endoscopy for financially needy elderly with financial assistance to pay Part B premiums that cover endoscopy services. Even with this assistance, dually eligible elderly in every state studied were significantly less likely to utilize endoscopy, ranging from about 3 to $12 \%$ lower probability of use and worsening over time (in most states) as the cohort aged. Apparently, there are other factors besides insurance coverage that impact utilization of these preventive services by financially needy elderly.

In contrast to an emerging literature finding positive spillover effects from managed care penetration on local area practices, we find that Medicare managed care penetration in the local primary care services market has negative spillovers on endoscopy utilization by FFS Medicare patients in several states (California, Connecticut, Louisiana, New Jersey, New Mexico, Utah, and Washington). The only state where spillovers are positive is Iowa. This negative spillover result is consistent with findings in a recent paper by Schneider et al. [44] that Medicare managed care practice favors FOBT over endoscopy use for persons enrolled in Medicare managed care organizations, when compared to FFS Medicare enrollees. Thus, Medicare managed care practices may have spilled over in the marketplace and discouraged the use of more expensive endoscopic procedures. Or, perhaps higher concentration among managed care insurers in some markets has limited the supply of endoscopic services by discouraging entry of providers. This negative spillover finding bears further investigation.

Our findings support the notion that places matterdifferent states show different relationships between CRC screening and ecological and market factors. It is important that policy interventions to improve screening rates reflect local population diversity and market conditions. Optimal policy interventions to change behavior (improve screening rates) will be as heterogeneous as regional populations and market conditions in the very diverse United States.

Acknowledgments This work was supported by a National Cancer Institute grant (1R01CA126858-01A1). The content is solely the responsibility of the authors and does not necessarily represent the official views of RTI International, the National Cancer Institute, or the National Institutes of Health. Contextual data used in this paper are part of a larger public use database, the RTI Spatial Impact Factor Database. To obtain data, visit our Web site (http://rtispatialdata.rti.org), financed by American Recovery and Reinvestment Act supplemental funding for 1R01CA126858-01A1.

Open Access This article is distributed under the terms of the Creative Commons Attribution Noncommercial License which permits any noncommercial use, distribution, and reproduction in any medium, provided the original author(s) and source are credited.

\section{Appendix}

See Tables 3, 4, 5 and 6.

Table 3 Variables chosen for analysis, their contextual relevance, and sources

\begin{tabular}{ll}
\hline Variable & Data source \\
\hline Individual and population & Developed from linked California SEER cancer \\
Enabling/disabling & registry and Medicare data, provided by the \\
Individual disability or ESRD as original reason for Medicare entitlement & National Cancer Institute, 2000-2003 \\
Moved to a new ZIP code in same state, 2000-2002 or 2003-2005 & \\
Months with extra assistance from state Medicaid (dual eligibility), 2000-2002 & \\
$\quad$ or 2003-2005 & \\
Distance to closest endoscopy facility &
\end{tabular}


Table 3 continued

\begin{tabular}{|c|c|}
\hline Variable & Data source \\
\hline \multicolumn{2}{|l|}{ Predisposing } \\
\hline \multicolumn{2}{|l|}{ Age in 2000} \\
\hline \multicolumn{2}{|l|}{ Months enrolled in a Medicare HMO anytime in 2000-2002 or 2003-2005 } \\
\hline \multicolumn{2}{|l|}{ Enrollment in Medicare HMO during the past 2 years } \\
\hline \multicolumn{2}{|l|}{$\begin{array}{l}\text { Race or ethnicity (white, African American, Asian, Hispanic, Native } \\
\text { American, other) }\end{array}$} \\
\hline \multicolumn{2}{|l|}{ Need } \\
\hline \multicolumn{2}{|l|}{ Had previous cancer diagnosis, breast or colorectal; had irritable bowel disease } \\
\hline \multicolumn{2}{|l|}{ Interpersonal factor (PCSA) } \\
\hline $\begin{array}{l}\text { Social integration and support: isolation index describing segregation by race } \\
\text { or ethnicity (white, African American, Asian, Hispanic, Native American, } \\
\text { other), } 2000\end{array}$ & $\begin{array}{l}\text { Developed from U.S. Census } 2000 \text { data at ZCTA } \\
\text { levels aggregated to PCSAs using HRSA's } \\
\text { crosswalk: http://datawarehouse.hrsa.gov/ }\end{array}$ \\
\hline \multicolumn{2}{|l|}{$\begin{array}{l}\text { Stressor, driver courtesy: commuter intensity reflecting the proportion of the } \\
\text { workforce in each person's residential area commuting } 60 \text { min or more each } \\
\text { way to work }\end{array}$} \\
\hline \multicolumn{2}{|l|}{$\begin{array}{l}\text { Social or cultural cohesion: proportion of the elderly in each person's } \\
\text { residential area with little or no English language ability, } 2000\end{array}$} \\
\hline $\begin{array}{l}\text { Local health norms and behaviors: Medicare managed care penetration, } \\
\text { defined as proportion of the eligible population enrolled in Medicare } \\
\text { managed care plans: } 2001 ; 2004\end{array}$ & $\begin{array}{l}\text { Built by RTI from } 100 \% \text { beneficiary denominator } \\
\text { files provided by the Centers for Medicare \& } \\
\text { Medicaid Services }\end{array}$ \\
\hline \multicolumn{2}{|l|}{ Intermediate/community factor (county) } \\
\hline $\begin{array}{l}\text { Proportion of population living below the federal poverty level; GINI coefficient } \\
\text { of household income disparity (calculated by RTI) }\end{array}$ & $\begin{array}{l}\text { Census annual poverty estimates; census } 2000 \\
\text { household income estimates }\end{array}$ \\
\hline $\begin{array}{l}\text { Health care system: number of endoscopy facilities per thousand elderly in each } \\
\text { person's residential area, 2000-2002, 2003-2005 }\end{array}$ & SEER-Medicare linked data and U.S. Census \\
\hline $\begin{array}{l}\text { Health care system: number of oncologists }(2000,2003) \text {, gastroenterologists } \\
(2000,2003) \text {, or nurses }(2000,2005) \text { per thousand elderly }(2000,2003)\end{array}$ & $\begin{array}{l}\text { Area resource file; annual census population } \\
\text { estimates }\end{array}$ \\
\hline
\end{tabular}

SEER surveillance, epidemiology, and end results, ZCTA ZIP code tabulation area, HRSA health resources and services administration, PCSA primary care service area

Table 4 Sample statistics for characteristics of sample population: mean followed by standard deviation

\begin{tabular}{|c|c|c|c|c|c|c|c|c|c|c|}
\hline \multirow{3}{*}{$\begin{array}{l}\text { Variable } \\
\text { Sample size }\end{array}$} & \multirow{2}{*}{\multicolumn{2}{|c|}{$\frac{\mathrm{CA}}{86,843}$}} & \multirow{2}{*}{\multicolumn{2}{|c|}{$\frac{\mathrm{CT}}{23,402}$}} & \multirow{2}{*}{\multicolumn{2}{|c|}{$\frac{\mathrm{GA}}{10,316}$}} & \multirow{2}{*}{\multicolumn{2}{|c|}{$\frac{\mathrm{IA}}{22,799}$}} & \multirow{2}{*}{\multicolumn{2}{|c|}{$\frac{\mathrm{KY}}{18,203}$}} \\
\hline & & & & & & & & & & \\
\hline & Mean & SD & Mean & SD & Mean & SD & Mean & SD & Mean & SD \\
\hline Female & 0.670 & 0.470 & 0.709 & 0.454 & 0.713 & 0.453 & 0.698 & 0.459 & 0.668 & 0.471 \\
\hline Disability or ESRD original reason for enrollment in Medicare & 0.002 & 0.050 & 0.004 & 0.062 & 0.003 & 0.057 & 0.004 & 0.065 & 0.001 & 0.036 \\
\hline Age $73-80$ in 2000 & 0.377 & 0.480 & 0.394 & 0.490 & 0.355 & 0.480 & 0.378 & 0.480 & 0.347 & 0.480 \\
\hline Age $80+$ in 2000 & 0.155 & 0.360 & 0.172 & 0.380 & 0.139 & 0.350 & 0.175 & 0.380 & 0.128 & 0.330 \\
\hline White & 0.789 & 0.408 & 0.945 & 0.229 & 0.783 & 0.412 & 0.986 & 0.117 & 0.946 & 0.227 \\
\hline Asian & 0.079 & 0.270 & 0.004 & 0.066 & 0.004 & 0.067 & 0.001 & 0.034 & 0.001 & 0.036 \\
\hline African American & 0.045 & 0.207 & 0.039 & 0.193 & 0.204 & 0.403 & 0.008 & 0.092 & 0.050 & 0.217 \\
\hline Hispanic & 0.048 & 0.214 & 0.006 & 0.077 & 0.003 & 0.058 & 0.001 & 0.027 & 0.000 & 0.017 \\
\hline Native American & 0.003 & 0.056 & 0.000 & 0.022 & 0.000 & 0.017 & 0.000 & 0.021 & 0.000 & 0.013 \\
\hline All other races/ethnicities & 0.036 & 0.185 & 0.006 & 0.077 & 0.005 & 0.071 & 0.003 & 0.056 & 0.003 & 0.052 \\
\hline Moved to new ZIP code $2000-2002$ & 0.073 & 0.261 & 0.060 & 0.237 & 0.084 & 0.277 & 0.030 & 0.172 & 0.037 & 0.189 \\
\hline Moved to new ZIP code $2003-2005$ & 0.089 & 0.285 & 0.051 & 0.220 & 0.088 & 0.284 & 0.045 & 0.208 & 0.046 & 0.209 \\
\hline Proportion of months with dual eligibility $2000-2002$ & 0.213 & 0.402 & 0.066 & 0.234 & 0.089 & 0.276 & 0.050 & 0.208 & 0.121 & 0.317 \\
\hline Proportion of months with dual eligibility 2003-2005 & 0.232 & 0.415 & 0.093 & 0.279 & 0.113 & 0.304 & 0.072 & 0.246 & 0.141 & 0.336 \\
\hline Average distance to closest endoscopy provider, 2000-2002 & 1.256 & 3.363 & 0.951 & 1.938 & 1.416 & 2.622 & 3.612 & 5.385 & 2.695 & 4.508 \\
\hline
\end{tabular}


Table 4 continued

\begin{tabular}{|c|c|c|c|c|c|c|c|c|c|c|}
\hline \multirow{3}{*}{$\begin{array}{l}\text { Variable } \\
\text { Sample size }\end{array}$} & \multirow{2}{*}{\multicolumn{2}{|c|}{$\frac{\mathrm{CA}}{86,843}$}} & \multirow{2}{*}{\multicolumn{2}{|c|}{$\frac{\mathrm{CT}}{23,402}$}} & \multirow{2}{*}{\multicolumn{2}{|c|}{$\frac{\mathrm{GA}}{10,316}$}} & \multirow{2}{*}{\multicolumn{2}{|c|}{$\frac{\text { IA }}{22,799}$}} & \multirow{2}{*}{\multicolumn{2}{|c|}{$\frac{\mathrm{KY}}{18,203}$}} \\
\hline & & & & & & & & & & \\
\hline & Mean & SD & Mean & SD & Mean & SD & Mean & SD & Mean & SD \\
\hline Average distance to closest endoscopy provider, 2003-2005 & 1.257 & 3.318 & 0.954 & 1.942 & 1.487 & 2.692 & 3.554 & 5.354 & 2.676 & 4.489 \\
\hline Had CRC diagnosis by 2002 & 0.138 & 0.345 & 0.192 & 0.394 & 0.155 & 0.362 & 0.203 & 0.402 & 0.120 & 0.325 \\
\hline Had CRC diagnosis by 2005 & 0.158 & 0.365 & 0.207 & 0.405 & 0.169 & 0.375 & 0.214 & 0.410 & 0.135 & 0.342 \\
\hline Had breast cancer diagnosis by 2002 & 0.227 & 0.419 & 0.293 & 0.455 & 0.273 & 0.446 & 0.272 & 0.445 & 0.150 & 0.357 \\
\hline Had breast cancer diagnosis by 2005 & 0.241 & 0.428 & 0.306 & 0.461 & 0.288 & 0.453 & 0.285 & 0.451 & 0.162 & 0.369 \\
\hline Had irritable bowel disease in $2000-2002$ & 0.015 & 0.123 & 0.014 & 0.116 & 0.013 & 0.112 & 0.009 & 0.094 & 0.012 & 0.111 \\
\hline Had irritable bowel disease in $2003-2005$ & 0.016 & 0.125 & 0.017 & 0.130 & 0.015 & 0.120 & 0.010 & 0.098 & 0.012 & 0.109 \\
\hline Had HMO coverage 1998-1999 & 0.151 & 0.358 & 0.234 & 0.423 & 0.113 & 0.317 & 0.009 & 0.095 & 0.039 & 0.194 \\
\hline Had HMO coverage 2001-2002 & 0.109 & 0.312 & 0.124 & 0.330 & 0.056 & 0.231 & 0.004 & 0.065 & 0.022 & 0.147 \\
\hline Months with MA HMO coverage, 2000-2002 & 2.787 & 7.748 & 3.794 & 8.079 & 1.860 & 6.035 & 0.094 & 1.307 & 0.616 & 3.531 \\
\hline Months with MA HMO coverage, 2003-2005 & 0.577 & 3.474 & 0.157 & 1.805 & 0.652 & 2.966 & 0.333 & 2.370 & 0.097 & 1.449 \\
\hline Months with no Part B coverage, 2000-2002 & 0.109 & 1.158 & 0.065 & 0.836 & 0.087 & 0.967 & 0.037 & 0.560 & 0.055 & 0.819 \\
\hline Months with no Part B coverage, 2003-2005 & 0.103 & 1.499 & 0.036 & 0.915 & 0.039 & 0.910 & 0.009 & 0.452 & 0.026 & 0.769 \\
\hline Variable & LA & & MI & & NJ & NI & & UT & & WA \\
\hline \multirow[t]{2}{*}{ Sample size } & \multicolumn{2}{|c|}{15,717} & \multicolumn{2}{|l|}{25,692} & 35,378 & \multicolumn{2}{|c|}{7,439} & \multicolumn{2}{|c|}{8,777} & 17,511 \\
\hline & \multicolumn{2}{|c|}{ Mean SD } & \multicolumn{2}{|c|}{ Mean SD } & \multicolumn{2}{|c|}{ Mean SD } & Mean SD & \multicolumn{2}{|c|}{ Mean SD } & Mean SD \\
\hline
\end{tabular}

Female

$\begin{array}{llllllllllll}0.678 & 0.467 & 0.713 & 0.453 & 0.673 & 0.469 & 0.655 & 0.475 & 0.674 & 0.469 & 0.696 & 0.460\end{array}$

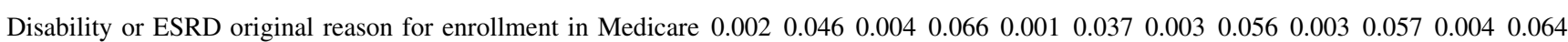
Age $73-80$ in 2000 $\begin{array}{lllllllllllll}0.346 & 0.480 & 0.387 & 0.490 & 0.384 & 0.490 & 0.342 & 0.470 & 0.360 & 0.480 & 0.384 & 0.490\end{array}$

Age $80+$ in 2000

White $\begin{array}{llllllllllll}0.126 & 0.330 & 0.151 & 0.360 & 0.145 & 0.350 & 0.128 & 0.330 & 0.141 & 0.350 & 0.158 & 0.360\end{array}$ $\begin{array}{llllllllllll}0.787 & 0.410 & 0.824 & 0.381 & 0.887 & 0.317 & 0.850 & 0.357 & 0.971 & 0.168 & 0.931 & 0.253\end{array}$

Asian

African American

Hispanic

Native American

All other races/ethnicities

Moved 2000-2002

Moved 2003-2005

Proportion of months with dual eligibility 2000-2002

Proportion of months with dual eligibility 2003-2005

Average distance to closest endoscopy provider, 2000-2002

Average distance to closest endoscopy provider, 2003-2005

Had CRC diagnosis by 2002

Had CRC diagnosis by 2005

Had breast cancer diagnosis by 2002

Had breast cancer diagnosis by 2005

Had irritable bowel disease in 2000-2002

Had irritable bowel disease in 2003-2005

Had HMO coverage 1998-1999

Had HMO coverage 2001-2002

Months with MA HMO coverage, 2000-2002

Months with MA HMO coverage, 2003-2005

$\begin{array}{llllllllllll}0.002 & 0.043 & 0.005 & 0.070 & 0.008 & 0.090 & 0.002 & 0.043 & 0.006 & 0.077 & 0.023 & 0.151\end{array}$ $\begin{array}{llllllllllll}0.203 & 0.402 & 0.163 & 0.369 & 0.079 & 0.270 & 0.012 & 0.108 & 0.003 & 0.052 & 0.018 & 0.134\end{array}$ $\begin{array}{lllllllllllllll}0.003 & 0.057 & 0.003 & 0.051 & 0.017 & 0.130 & 0.090 & 0.286 & 0.009 & 0.094 & 0.003 & 0.052\end{array}$ $\begin{array}{llllllllllll}0.001 & 0.035 & 0.000 & 0.020 & 0.000 & 0.018 & 0.038 & 0.191 & 0.003 & 0.056 & 0.006 & 0.077\end{array}$ $\begin{array}{llllllllllll}0.004 & 0.063 & 0.006 & 0.075 & 0.008 & 0.090 & 0.009 & 0.092 & 0.008 & 0.090 & 0.018 & 0.133\end{array}$ $\begin{array}{llllllllllll}0.039 & 0.195 & 0.070 & 0.255 & 0.060 & 0.238 & 0.078 & 0.269 & 0.046 & 0.210 & 0.086 & 0.280\end{array}$ $\begin{array}{llllllllllll}0.054 & 0.226 & 0.071 & 0.257 & 0.060 & 0.238 & 0.059 & 0.236 & 0.068 & 0.252 & 0.093 & 0.291\end{array}$ $\begin{array}{llllllllllll}0.155 & 0.352 & 0.062 & 0.234 & 0.073 & 0.252 & 0.121 & 0.317 & 0.032 & 0.170 & 0.062 & 0.233\end{array}$ $\begin{array}{llllllllllll}0.185 & 0.379 & 0.070 & 0.247 & 0.090 & 0.278 & 0.143 & 0.340 & 0.043 & 0.193 & 0.078 & 0.258\end{array}$ $\begin{array}{llllllllllll}3.158 & 5.704 & 0.653 & 1.861 & 0.791 & 1.668 & 4.715 & 9.935 & 1.926 & 5.330 & 1.554 & 3.404\end{array}$ $\begin{array}{llllllllllll}3.127 & 5.674 & 0.680 & 1.941 & 0.792 & 1.687 & 4.733 & 9.809 & 1.916 & 5.302 & 1.554 & 3.362\end{array}$ $\begin{array}{llllllllllll}0.112 & 0.316 & 0.176 & 0.381 & 0.133 & 0.340 & 0.141 & 0.348 & 0.135 & 0.342 & 0.159 & 0.366\end{array}$ $\begin{array}{lllllllllllll}0.126 & 0.332 & 0.197 & 0.397 & 0.151 & 0.358 & 0.153 & 0.360 & 0.147 & 0.354 & 0.172 & 0.377\end{array}$ $\begin{array}{llllllllllll}0.147 & 0.354 & 0.291 & 0.454 & 0.160 & 0.366 & 0.248 & 0.432 & 0.266 & 0.442 & 0.316 & 0.465\end{array}$ $\begin{array}{llllllllllll}0.162 & 0.368 & 0.306 & 0.461 & 0.174 & 0.379 & 0.260 & 0.439 & 0.279 & 0.449 & 0.329 & 0.470\end{array}$ $\begin{array}{llllllllllll}0.009 & 0.096 & 0.016 & 0.126 & 0.018 & 0.134 & 0.013 & 0.112 & 0.012 & 0.108 & 0.013 & 0.113\end{array}$ $\begin{array}{llllllllllll}0.010 & 0.098 & 0.018 & 0.135 & 0.020 & 0.138 & 0.014 & 0.117 & 0.014 & 0.118 & 0.013 & 0.113\end{array}$ $\begin{array}{llllllllllll}0.157 & 0.364 & 0.070 & 0.255 & 0.131 & 0.337 & 0.093 & 0.291 & 0.126 & 0.332 & 0.154 & 0.361\end{array}$ $\begin{array}{llllllllllll}0.086 & 0.280 & 0.076 & 0.266 & 0.071 & 0.258 & 0.023 & 0.150 & 0.007 & 0.084 & 0.057 & 0.232\end{array}$ $\begin{array}{llllllllllll}1.973 & 6.121 & 1.747 & 6.130 & 1.861 & 6.162 & 1.143 & 4.112 & 0.130 & 1.579 & 2.044 & 5.942\end{array}$ $\begin{array}{llllllllllll}0.410 & 2.815 & 0.078 & 1.100 & 0.229 & 2.132 & 0.833 & 4.349 & 0.347 & 1.908 & 0.261 & 2.386\end{array}$ $\begin{array}{llllllllllll}0.066 & 0.843 & 0.068 & 0.886 & 0.086 & 0.981 & 0.076 & 0.889 & 0.090 & 1.024 & 0.066 & 0.841\end{array}$ $\begin{array}{llllllllllll}0.027 & 0.758 & 0.024 & 0.715 & 0.044 & 1.014 & 0.044 & 1.029 & 0.040 & 1.013 & 0.044 & 0.976\end{array}$ 
Table 5 Sample statistics for interpersonal factors (PCSAs): means followed by standard deviations

\begin{tabular}{|c|c|c|c|c|c|c|c|c|c|c|c|c|}
\hline \multirow{3}{*}{$\begin{array}{l}\text { State } \\
\text { Number PCSAs }\end{array}$} & \multicolumn{2}{|l|}{ CA } & \multicolumn{3}{|l|}{$\mathrm{CT}$} & \multicolumn{2}{|c|}{ GA } & \multicolumn{2}{|l|}{ IA } & \multicolumn{2}{|l|}{ KY } & \\
\hline & \multicolumn{2}{|l|}{336} & \multicolumn{3}{|l|}{71} & \multicolumn{2}{|c|}{116} & \multicolumn{2}{|l|}{224} & \multicolumn{2}{|l|}{144} & \\
\hline & Mean & SD & Mear & SD & $\mathrm{Me}$ & an & SD & Mean & SD & Mean & SD & \\
\hline Isolation index for African Americans & 0.050 & 0.078 & 0.068 & 0.1 & 0.2 & & 0.192 & 0.011 & 0.036 & 0.059 & 0.094 & \\
\hline Isolation index for Hispanics & 0.311 & 0.237 & 0.077 & 0.1 & 0.0 & & 0.051 & 0.024 & 0.038 & 0.015 & 0.014 & \\
\hline Isolation index for Asians & 0.067 & 0.085 & 0.023 & 0.0 & 0.0 & & 0.016 & 0.007 & 0.009 & 0.006 & 0.010 & \\
\hline Isolation index for native Americans & 0.022 & 0.057 & 0.004 & 0.0 & 0.0 & & 0.003 & 0.004 & 0.011 & 0.004 & 0.005 & \\
\hline Proportion of workforce who commute $>60 \mathrm{~min}$ & 0.102 & 0.059 & 0.086 & 0.0 & 0.0 & & 0.042 & 0.049 & 0.026 & 0.094 & 0.048 & \\
\hline $\begin{array}{l}\text { Proportion of elderly with little/no English } \\
\text { language }\end{array}$ & 0.286 & 0.168 & 0.152 & 0.0 & 0.2 & & 0.199 & 0.081 & 0.130 & 0.104 & 0.155 & \\
\hline Prop. area's beneficiaries in Medicare HMO 2001 & 0.308 & 0.201 & 0.082 & 0.0 & 0.0 & & 0.045 & 0.024 & 0.052 & 0.034 & 0.058 & \\
\hline Prop. area's beneficiaries in Medicare HMO 2004 & 0.277 & 0.185 & 0.059 & 0.0 & 0.0 & & 0.030 & 0.056 & 0.063 & 0.043 & 0.048 & \\
\hline State & LA & & MI & & NJ & & NM & & UT & & WA & \\
\hline \multirow[t]{2}{*}{ Number PCSAs } & \multicolumn{2}{|l|}{109} & \multicolumn{2}{|l|}{148} & \multicolumn{2}{|l|}{141} & \multicolumn{2}{|l|}{61} & \multicolumn{2}{|l|}{50} & \multicolumn{2}{|l|}{110} \\
\hline & Mean & SD & Mean & SD & Mean & SD & Mea & SD & Mean & SD & Mean & SD \\
\hline Isolation index for African Americans & 0.357 & 0.172 & 0.086 & 0.172 & 0.125 & 0.158 & 0.01 & 0.018 & 0.006 & 0.014 & 0.019 & 0.037 \\
\hline Isolation index for Hispanics & 0.020 & 0.017 & 0.034 & 0.044 & 0.121 & 0.144 & 0.50 & 0.219 & 0.096 & 0.094 & 0.088 & 0.125 \\
\hline Isolation index for Asians & 0.011 & 0.031 & 0.011 & 0.017 & 0.053 & 0.055 & 0.00 & 0.008 & 0.010 & 0.011 & 0.031 & 0.043 \\
\hline Isolation index for native Americans & 0.012 & 0.028 & 0.013 & 0.026 & 0.002 & 0.002 & 0.13 & 0.271 & 0.026 & 0.060 & 0.055 & 0.130 \\
\hline Prop. workforce who commute $>60 \mathrm{~min}$ & 0.101 & 0.041 & 0.072 & 0.040 & 0.130 & 0.053 & 0.09 & 0.073 & 0.074 & 0.047 & 0.097 & 0.073 \\
\hline Proportion of elderly with little/no English & 0.085 & 0.106 & 0.112 & 0.088 & 0.242 & 0.137 & 0.25 & 0.210 & 0.172 & 0.199 & 0.192 & 0.164 \\
\hline Prop. area's beneficiaries in Medicare HMO 2001 & 0.081 & 0.131 & 0.021 & 0.036 & 0.116 & 0.048 & 0.05 & 0.110 & 0.037 & 0.057 & 0.151 & 0.137 \\
\hline Prop. area's beneficiaries in Medicare HMO 2004 & 0.082 & 0.127 & 0.026 & 0.028 & 0.094 & 0.036 & 0.08 & 0.112 & 0.085 & 0.052 & 0.138 & 0.110 \\
\hline
\end{tabular}

Table 6 Sample statistics for intermediate/community factors (counties): mean followed by standard deviation

\begin{tabular}{|c|c|c|c|c|c|c|c|c|c|c|c|c|}
\hline \multirow{3}{*}{$\begin{array}{l}\text { State } \\
\text { Number of counties }\end{array}$} & \multirow{2}{*}{\multicolumn{2}{|c|}{$\frac{\mathrm{CA}}{58}$}} & \multirow{2}{*}{\multicolumn{2}{|c|}{$\frac{\mathrm{CT}}{8}$}} & \multirow{2}{*}{\multicolumn{3}{|c|}{$\frac{\mathrm{GA}}{118}$}} & \multirow{2}{*}{\multicolumn{2}{|c|}{$\frac{\text { IA }}{99}$}} & \multirow{2}{*}{\multicolumn{2}{|c|}{$\frac{\mathrm{KY}}{120}$}} & \\
\hline & & & & & & & & & & & & \\
\hline & Mean & SD & Mean & SD & Mean & & SD & Mean & SD & Mean & SD & \\
\hline Percent population in poverty 2000 & 13.419 & 4.890 & 6.513 & 1.758 & 15.01 & & 5.386 & 8.792 & 2.032 & 16.698 & 6.411 & \\
\hline Percent population in poverty 2003 & 12.853 & 3.820 & 7.063 & 1.723 & 15.38 & & 4.671 & 9.026 & 1.789 & 16.892 & 5.379 & \\
\hline Gini coefficient of income disparity, 2000 & 0.448 & 0.023 & 0.429 & 0.041 & 0.44 & & 0.044 & 0.404 & 0.022 & 0.457 & 0.040 & \\
\hline $\begin{array}{l}\text { Endoscopic providers per thousand, 2000- } \\
2002\end{array}$ & 1.059 & 0.527 & 1.483 & 0.594 & 0.54 & & 0.830 & 1.560 & 1.294 & 1.014 & 0.951 & \\
\hline $\begin{array}{l}\text { Endoscopic providers per thousand, 2003- } \\
2005\end{array}$ & 1.841 & 3.946 & 0.928 & 0.728 & 4.11 & & 10.983 & 2.208 & 3.272 & 2.826 & 15.999 & \\
\hline Oncologists per thousand, 2000 & 0.074 & 0.067 & 0.092 & 0.081 & 0.04 & & 0.102 & 0.035 & 0.147 & 0.029 & 0.083 & \\
\hline Oncologists per thousand, 2003 & 0.170 & 0.142 & 0.304 & 0.201 & 0.11 & & 0.202 & 0.064 & 0.284 & 0.067 & 0.176 & \\
\hline Gastroenterologists per thousand, 2000 & 0.078 & 0.070 & 0.098 & 0.087 & 0.05 & & 0.103 & 0.027 & 0.116 & 0.028 & 0.088 & \\
\hline Gastroenterologists per thousand, 2003 & 0.178 & 0.157 & 0.333 & 0.200 & 0.13 & & 0.229 & 0.072 & 0.347 & 0.068 & 0.158 & \\
\hline State & LA & & MI & & NJ & & NM & & UT & & WA & \\
\hline \multirow[t]{2}{*}{ Number of counties } & \multicolumn{2}{|l|}{64} & \multicolumn{2}{|l|}{78} & \multicolumn{2}{|l|}{21} & \multicolumn{2}{|l|}{33} & \multicolumn{2}{|l|}{29} & \multicolumn{2}{|l|}{39} \\
\hline & Mean & SD & Mean & SD & Mean & SD & Mean & SD & Mean & SD & Mean & SD \\
\hline Percent population in poverty 2000 & 19.281 & 5.475 & 10.355 & 2.894 & 7.500 & 3.460 & $50 \quad 19.670$ & 5.308 & $8 \quad 11.272$ & 24.177 & 12.663 & 3.332 \\
\hline Percent population in poverty 2003 & 19.169 & 4.329 & 10.769 & 2.424 & 8.550 & 3.540 & 1018.918 & 4.957 & 710.717 & 73.560 & 12.664 & 2.651 \\
\hline
\end{tabular}


Table 6 continued

\begin{tabular}{|c|c|c|c|c|c|c|c|c|c|c|c|c|}
\hline \multirow{3}{*}{$\begin{array}{l}\text { State } \\
\text { Number of counties }\end{array}$} & \multirow{2}{*}{\multicolumn{2}{|c|}{$\frac{\mathrm{LA}}{64}$}} & \multirow{2}{*}{\multicolumn{2}{|c|}{$\frac{\mathrm{MI}}{78}$}} & \multirow{2}{*}{\multicolumn{2}{|c|}{$\frac{\mathrm{NJ}}{21}$}} & \multirow{2}{*}{\multicolumn{2}{|c|}{$\frac{\mathrm{NM}}{33}$}} & \multirow{2}{*}{\multicolumn{2}{|c|}{$\frac{\mathrm{UT}}{29}$}} & \multirow{2}{*}{\multicolumn{2}{|c|}{$\frac{\text { WA }}{39}$}} \\
\hline & & & & & & & & & & & & \\
\hline & Mean & SD & Mean & SD & Mean & SD & Mean & SD & Mean & SD & Mean & SD \\
\hline Gini coefficient of income disparity, 2000 & 0.468 & 0.033 & 0.414 & 0.022 & 0.432 & 0.036 & 0.450 & 0.033 & 0.400 & 0.031 & 0.428 & 0.030 \\
\hline Endoscopic providers per thousand, 2000-2002 & 1.129 & 1.112 & 0.433 & 0.643 & 1.109 & 0.344 & 1.034 & 0.730 & 1.188 & 1.206 & 0.877 & 0.766 \\
\hline Endoscopic providers per thousand, 2003-2005 & 2.500 & 5.799 & 4.616 & 16.157 & 1.273 & 0.735 & 5.680 & 17.338 & 2.867 & 8.172 & 6.912 & 18.612 \\
\hline Oncologists per thousand, 2000 & 0.026 & 0.063 & 0.049 & 0.139 & 0.080 & 0.058 & 0.023 & 0.053 & 0.018 & 0.049 & 0.054 & 0.077 \\
\hline Oncologists per thousand, 2003 & 0.089 & 0.173 & 0.087 & 0.214 & 0.339 & 0.186 & 0.078 & 0.126 & 0.135 & 0.403 & 0.143 & 0.187 \\
\hline Gastroenterologists per thousand, 2000 & 0.028 & 0.072 & 0.048 & 0.138 & 0.095 & 0.073 & 0.018 & 0.047 & 0.042 & 0.118 & 0.050 & 0.071 \\
\hline Gastroenterologists per thousand, 2003 & 0.098 & 0.188 & 0.092 & 0.245 & 0.368 & 0.194 & 0.087 & 0.152 & 0.107 & 0.259 & 0.144 & 0.183 \\
\hline
\end{tabular}

\section{References}

1. Horner MJ, Ries LAG, Krapcho M, et al (eds) (2009) SEER cancer statistics review, 1975-2006. National Cancer Institute, Bethesda, MD. Available from, http://seer.cancer.gov/csr/1975_2006/results_ merged/topic_age_dist.pdf

2. Ries LAG, Eisner MP, Kosary CL et al (eds) (2005) SEER cancer statistics review, 1975-2002. National Cancer Institute, Bethesda

3. Winawer SJ, Fletcher RH, Miller L et al (1997) Colorectal cancer screening: clinical guidelines and rationale. Gastroenterology 112(2):594-642

4. American Cancer Society (ACS) (2006) Cancer prevention and early detection facts and figures 2006 [web page]. Accessed 14 August 2009, from, http://www.cancer.org/downloads/STT/CPED2006PW Secured.pdf

5. Centers for Disease Control and Prevention (CDC) (2006) Increased use of colorectal cancer tests-United States, 2002, 2004 and 2006. MMWR 57(10):253-258

6. Centers for Disease Control and Prevention (CDC) (2004) Increased use of colorectal cancer tests-United States, 2002 and 2004. MMWR 55(11):308-311

7. Meissner HI, Breen N, Klabunde CN, Vernon SW (2006) Patterns of colorectal cancer screening uptake among men and women in the United States. Cancer Epidemiol Biomarkers Prev 15(2): 389-394

8. Ata A, Elzey JD, Insaf TZ et al (2006) Colorectal cancer prevention: adherence patterns and correlates of tests done for screening purposes within United States populations. Cancer Detect Prev 30(2):134-143

9. Seeff LC, Nadel MR, Klabunde CN et al (2004) Patterns and predictors of colorectal cancer test use in the adult U.S. population. Cancer 100(10):2093-2103

10. Klabunde C, Lanier D, Meissner HI, Breslau ES, Brown ML (2008) Improving colorectal cancer screening through research in primary care settings. Med Care 46:S1-S4

11. American Cancer Society (2009) Cancer facts and figures 2009. American Cancer Society, Atlanta, GA. Available from, http://www.cancer.org/downloads/STT/500809web.pdf

12. Tang LY, Nugent Z, Demers AA, Singh H (2009) Incidence of right-sided colorectal cancer after breast cancer: a populationbased study. Am J Gastroenterol 104(5):1213-1220

13. Niell B, Rennert G, Bonner JD, Almog R, Tomsho LP, Gruber SB (2004) BRCA1 and BRCA2 founder mutations and the risk of colorectal cancer. J Natl Cancer Inst 96(1):15-21

14. Jang J, Cotterchio M, Gallinger S, Knight JA, Daftary D (2009) Family history of hormonal cancers and colorectal cancer risk: a case-control study conducted in Ontario. Int J Cancer 125(4): 918-925

15. Lin KM, Ternent CA, Adams DR et al (1999) Colorectal cancer in hereditary breast cancer kindreds. Dis Colon Rectum 42(8):1041-1045

16. Garcia-Patino E, Gomendio B (1998) Loss of heterozygosity in the region including the BRCA1 gene on $17 \mathrm{~g}$ in colon cancer. Cancer Genet Cytogenet 104(2):119-123

17. National Cancer Institute (NCI) (2009) Colorectal cancer screening $\left(\mathrm{PDQ}^{\circledR}\right)$. http://www.cancer.gov/cancertopics/pdq/ screening/colorectal/HealthProfessional/page3. Accessed August 2009

18. Gillen CD, Walmsley RS, Prior P, Andrews HA, Allan RN (1994) Ulcerative colitis and Crohn's disease: a comparison of the colorectal cancer risk in extensive colitis. Gut 35(11):1590 1592

19. Ekbom A, Helmick C, Zack M, Adami HO (1990) Ulcerative colitis and colorectal cancer. A population-based study. N Engl J Med 323(18):1228-1233

20. Rex DK, Kahi CJ, Levin B et al (2006) Guidelines for colonoscopy surveillance after cancer resection: a consensus update by the American Cancer Society and the US Multi-Society Task Force on Colorectal Cancer. Gastroenterology 130(6):1865-1871

21. Hassan C, Pickhardt PJ, Zullo A, et al (2009) Cost-effectiveness of early colonoscopy surveillance after cancer resection. Dig Liver Dis [Epub ahead of print]

22. Cooper GS, Koroukian SM (2004) Geographic variation among Medicare beneficiaries in the use of colorectal carcinoma screening procedures. Am J Gastroenterol 99(8):1544-1550

23. Ko CW, Kreuter W, Baldwin LM (2005) Persistent demographic differences in colorectal cancer screening utilization despite Medicare reimbursement. BMC Gastroenterol 5(1):10

24. Sardinha TC, Nogueras JJ, Ehrenpreis EE et al (1999) Colonoscopy in octogenarians: a review of 428 cases. Int J Colorectal Dis 14(3):172-176

25. Whitlock EP, Lin JS, Liles E, Beil TL, Fu R (2008) Screening for colorectal cancer: a targeted, updated systematic review for the U.S. Preventive Services Task Force. Ann Intern Med 149(9): 638-658

26. Warren JL, Klabunde CN, Mariotto AB et al (2009) Adverse events after outpatient colonoscopy in the Medicare population. Ann Intern Med 150(12):849-857

27. Pope G, Greenwald L, Kautter J, Olmstead E, Mobley L (2006) Medicare preferred provider organization demonstration: plan offerings and beneficiary enrollment. Health Care Financ Rev 27(3):95-109 
28. Mobley LR, McCormack LA, Wang J et al (2007) Voluntary disenrollment from Medicare advantage plans: valuable signals of market performance. Am J Manag Care 13(12):677-684

29. Mobley LR, Kuo TM, Clayton LJ, Evans WD (2009) Mammography facilities are accessible, so why is utilization so low? Cancer Causes Control 20(6):1017-1028

30. Mobley LR, Kuo TM, Andrews L (2008) How sensitive are multilevel regression findings to defined area of context? A case study of mammography use in California. Med Care Res Rev 65(3):315-337

31. Mobley LR, Kuo TM, Driscoll D, Clayton L, Anselin L (2008) Heterogeneity in mammography use across the nation: separating evidence of disparities from the disproportionate effects of geography. Int J Health Geogr 7:32

32. Aday LA, Andersen R (1974) A framework for the study of access to medical care. Health Serv Res 9(3):208-220

33. Goodman DC, Mick SS, Bott D et al (2003) Primary care service areas: a new tool for the evaluation of primary care services. Health Serv Res 38(1 Pt 1):287-309

34. Mobley LR, Root E, Anselin L, Lozano-Gracia N, Koschinsky J (2006) Spatial analysis of elderly access to primary care services. Int J Health Geogr 5:19

35. Hardin JW, Hilbe JM (2003) Generalized estimating equations. Chapman \& Hall/CRC, New York

36. Horton NJ, Lipsitz SR (1999) Review of software to fit generalized estimation equation regression models. Am Stat 53:60-169

37. Liang K-Y, Zeger SL (1986) Longitudinal data analysis using generalized linear models. Biometrika 73(1):13-22

38. Massey DS, Denton NA (1988) The dimensions of residential segregation. Soc Forces 7:281-315

39. Baker LC (2003) Managed care spillover effects. Annu Rev Public Health 24:435-456

40. Decker SL, Hempstead K (1999) HMO penetration and quality of care: the case of breast cancer. J Health Care Finance 26(1):18-32

41. Baker LC, Phillips KA, Haas JS, Liang SY, Sonneborn D (2004) The effect of area HMO market share on cancer screening. Health Serv Res 39(6 Part 1):1751-1772

42. Baker LC, Brown ML (1999) Managed care, consolidation among health care providers, and health care: evidence from mammography. Rand J Econ 30(2):351-374

43. Gordon NP, Rundall TG, Parker L (1998) Type of health care coverage and the likelihood of being screened for cancer. Med Care 36(5):636-645

44. Schneider EC, Rosenthal M, Gatsonis CG, Zheng J, Epstein AM (2008) Is the type of Medicare insurance associated with colorectal cancer screening prevalence and selection of screening strategy? Med Care 46(9 Suppl 1):S84-S90

45. Ponce NA, Huh S, Bastani R (2005) Do HMO market level factors lead to racial/ethnic disparities in colorectal cancer screening? A comparison between high-risk Asian and Pacific Islander Americans and high-risk whites. Med Care 43(11):1101-1108

46. Warren JL, Klabunde CN, Schrag D, Bach PB, Riley GF (2002) Overview of the SEER-Medicare data: content, research applications, and generalizability to the United States elderly population. Med Care 40(8 Suppl):IV-3-IV-18

47. Williams DR, Collins C (2001) Racial residential segregation: a fundamental cause of racial disparities in health. Public Health Rep 116(5):404-416

48. Schulz AJ, Williams DR, Israel BA, Lempert LB (2002) Racial and spatial relations as fundamental determinants of health in Detroit. Milbank Q 80(4):677-707

49. Palloni A, Arias E (2004) Paradox lost: explaining the Hispanic adult mortality advantage. Demography 41(3):385-415

50. Mobley LR, Root ED, Finkelstein EA, Khavjou O, Farris RP, Will JC (2006) Environment, obesity, and cardiovascular disease risk in low-income women. Am J Prev Med 30(4):327-332

51. Afable-Munsuz A, Liang SY, Ponce NA, Walsh JM (2009) Acculturation and colorectal cancer screening among older Latino adults: differential associations by national origin. J Gen Intern Med 24(8):963-970 (Epub 2009 May 27)

52. Seeff LC, Manninen DL, Dong FB et al (2004) Is there endoscopic capacity to provide colorectal cancer screening to the unscreened population in the United States? Gastroenterology 127(6):1661-1669

53. Seeff LC, Tangka FK (2005) Can we predict the outcomes of national colorectal cancer screening and can predictions help us plan? Gastroenterology 129(4):1339-1342

54. Tangka FK, Molinari NA, Chattopadhyay SK, Seeff LC (2005) Market for colorectal cancer screening by endoscopy in the United States. Am J Prev Med 29(1):54-60

55. Levin TR (2004) Colonoscopy capacity: can we build it? Will they come? Gastroenterology 127(6):1841-1844

56. Ladabaum U, Song K (2005) Projected national impact of colorectal cancer screening on clinical and economic outcomes and health services demand. Gastroenterology 129(4):1151-1162

57. Vijan S, Inadomi J, Hayward RA, Hofer TP, Fendrick AM (2004) Projections of demand and capacity for colonoscopy related to increasing rates of colorectal cancer screening in the United States. Aliment Pharmacol Ther 20(5):507-515 